\title{
Differential access to facilities for medical termination of pregnancy and delivery in India: A secondary analysis
}

\author{
Shantanu Sharma ${ }^{\text {a, }, ~}$ Ajit Kumar Jaiswal ${ }^{\text {b }}$, Rajesh Kumar Singh ${ }^{\text {a }}$, Paramhans Kumar ${ }^{\text {a }}$, \\ Sunil Mehra ${ }^{a}$ \\ ${ }^{\text {a }}$ MAMTA Health Institute of Mother and Child, Delhi, India \\ ${ }^{\mathrm{b}}$ International Institute for Population Sciences, Mumbai, India
}

\section{A R T I C L E I N F O}

\section{Keywords:}

Abortion

Maternal health

Pregnancy

Women

\begin{abstract}
A B S T R A C T
Introduction: Emerging evidence suggests a difference in access to facilities for medical termination of pregnancy (MTP) and delivery among women in different regions of the country. However, we lack assessments at a large scale across all geographies. Our study aims to describe the percent contribution of private and public sectors in institutional deliveries and MTP in India.

Methods: A secondary data analysis using the Health Management Information System statistics was performed. We obtained selective data regarding the total number of MTP and deliveries conducted at public and private institutions. The standard reports of the period between April 2018 and March 2019 were analyzed. The states (n $=29$ ) and union territories $(n=7)$ were dichotomized into regions, namely north, south, east, west, north-east, and central.

Results: A large part of women underwent deliveries and abortions in the private sector in the southern and western states of India like Kerala, Tamil Nadu, Andhra Pradesh, Goa, and Maharashtra. Women in most of the northern states opted for public facilities for deliveries as well as abortions, except Punjab and Haryana. On the contrary, states like Bihar, Nagaland, and Union territories like Delhi and Dadra and Nager Haveli had a high percentage of abortions in the private sector and deliveries in public health facilities.

Conclusion: This differential access highlights the need to assess the underlying factors for immediate actions by the policy-makers. Ensuring safe and good quality delivery and abortion services is the means to assure the sexual and reproductive health rights of women by the government.
\end{abstract}

\section{Introduction}

Constituting the world's $17 \%$ of the population, India holds the key to the achievement of global Sustainable Development Goals (SDG). ${ }^{1}$ Notably, the nation has strengthened its maternal health governance through national health programs to address health and social inequalities for achieving SDG. ${ }^{2}$ According to the World Health Organization (WHO), India made considerable progress in reducing the maternal mortality rate by $77 \%$ in the past two decades. ${ }^{3}$ Three states, including Kerala, Maharashtra, and Tamil Nadu, have already reached the SDG-3 target of the maternal mortality rate of less than 70 per 1,00 , 000 live births, and the other eight states have reduced MMR to less than 100 per 1,00,000 live births. ${ }^{4}$ The Reproductive, Maternal, Newborn, Child, and Adolescent Health (RMNCH + A) strategy profoundly impacted the country's maternal health situation. Despite the lack of inter-ministerial coordination and inadequate convergence between allied departments, the states managed to improve maternal health steadily. ${ }^{2,4}$

Universal coverage of institutional delivery can reduce maternal deaths significantly. In India, the institutional delivery rate increased substantially from $43 \%$ in 2004 to $82 \%$ in $2014 .^{5}$ The public sector contributes to nearly $50 \%$ of the institutional deliveries compared to $30 \%$ by the private sector. This difference in access to public or private facilities was associated with the substantial uptake in public sector services among the poor. ${ }^{6}$ Furthermore, private sector uptake for institutional delivery varies between rural and urban areas. Attempts have been made to leverage the use of the private sector for complementing the public sector in areas where it is inadequate and ensuring women,

\footnotetext{
* Corresponding author.

E-mail addresses: shantanusharma145@gmail.com, shantanusharma@mamtahimc.org (S. Sharma), ajitjaiswal20@gmail.com (A.K. Jaiswal), rksingh@ mamtahimc.in (R.K. Singh), param@mamtahimc.in (P. Kumar), dr_mehra@mamtahimc.in (S. Mehra).
} 
especially of lower socio-economic strata, in accessing services at private facilities free from financial implications. ${ }^{7}$

The government of India's flagship program, Janani Suraksha Karyakaram (conditional cash transfer scheme), linked cash assistance to support the increment in institutional delivery rates. ${ }^{8}$ However, studies have highlighted inequalities in access to the cash transfer scheme among different states. ${ }^{9,10}$ Partnership with the private sector was ensued in the cash transfer scheme to improve the reach and quality of the services. Still, it did not achieve the desired success due to unattractive offers, inadequate use, and delayed reimbursements. ${ }^{7}$

Like institutional delivery, the uptake of Medical Termination of Pregnancy (MTP) services is increasing in the country. ${ }^{11}$ Factors such as increased awareness of women about the legality of MTP, providers' knowledge about its safety and efficacy, and improved availability of medical abortifacients have contributed to its increased uptake. The MTP act that came into enforcement in 1971 aims to improve access of women to safe abortion services under specific conditions. However, there has been restricted access to MTP services contrary to the demand due to limited availability of accredited institutions, competent doctors that could perform MTP, and stigma among patients and centers providing these services. Consequently, illegal abortions are widely prevalent both in urban and rural areas. ${ }^{12}$ Furthermore, despite the current recommendations suggesting using oral abortifacient tablets under medical supervision, they are available over the counter without the need to visit a hospital. ${ }^{13}$

Studies highlighted that though the access to public health facilities for MTP has increased in the past few years, the percentage of women accessing private facilities far exceeds those who access the public sector. ${ }^{14}$ Women entrust private facilities to ensure privacy and confidentiality while providing abortion services compared to public facilities. ${ }^{12,14}$ Moreover, there is a lack of MTP facilities in rural areas, and women access urban private facilities to seek an abortion. There is a wide variation in the quality of MTP services across states in India. ${ }^{15}$

There is increasing evidence from small-scale studies and national health surveys that documented differential access to facilities for institutional deliveries and MTP. However, we lack assessments at a large scale across all geographies that compare this differential access. This paper aims to describe the percent contribution of private and public sectors in institutional deliveries and medical termination of pregnancy across the states in India.

\section{Material and methods}

\subsection{Data management}

India, with a population of 1.36 billion, has 29 states and 7 union territories. ${ }^{16,17}$ The public health service delivery model in India is a vertical 3-tier system, including primary, secondary, and tertiary levels of healthcare. Primary healthcare is provided by primary health centers and sub-centers in villages, secondary healthcare by community health centers, and tertiary healthcare by tertiary hospitals, specialized hospitals, and apex institutes or teaching medical colleges. ${ }^{18}$ In the mixed-health system of India, the private sector is a major stakeholder, contributing to more than $80 \%$ of services in India. ${ }^{19}$ Though the private sector is supposed to be equally governed and monitored by the government, the implementation of the same has been questioned in various studies. $^{20}$

We conducted a secondary data analysis using the Health Management Information System (HMIS) statistics of 2018-2019. The HMIS data is freely available for research purposes. ${ }^{21}$ The HMIS is a Government to Government (G2G) web-based monitoring information system that has been put in place by the Ministry of Health \& Family Welfare (MoHFW), Government of India, to monitor the National Health Mission. The HMIS portal facilitates the flow of physical performance from the facility level to the sub-district, district, state, and national level using a web-based interface. The portal provides periodic reports in
Table 1

State-wise distribution of the percentage of institutional delivery across public and private facilities.

\begin{tabular}{|c|c|c|c|c|}
\hline States & $\begin{array}{l}\text { Total } \\
\text { reported } \\
\text { deliveries }\end{array}$ & $\begin{array}{l}\% \text { of } \\
\text { institutional } \\
\text { deliveries to } \\
\text { total reported } \\
\text { deliveries }\end{array}$ & $\begin{array}{l}\text { \% Deliveries } \\
\text { conducted at } \\
\text { Public } \\
\text { Institutions to } \\
\text { Total } \\
\text { Institutional } \\
\text { Deliveries }\end{array}$ & $\begin{array}{l}\% \text { Deliveries } \\
\text { conducted at } \\
\text { Private } \\
\text { Institutions to } \\
\text { Total } \\
\text { Institutional } \\
\text { Deliveries }\end{array}$ \\
\hline \multicolumn{5}{|l|}{ North } \\
\hline Chandigarh & 29021 & 99.8 & 100.0 & 0 \\
\hline Delhi & 283717 & 95.7 & 81.2 & 18.8 \\
\hline Haryana & 500821 & 94.9 & 60.4 & 39.6 \\
\hline $\begin{array}{l}\text { Himachal } \\
\text { Pradesh }\end{array}$ & 87392 & 90.4 & 85.4 & 14.6 \\
\hline $\begin{array}{c}\text { Jammu and } \\
\text { Kashmir }\end{array}$ & 199384 & 94.8 & 91.0 & 9.0 \\
\hline Punjab & 372882 & 97.7 & 51.4 & 48.6 \\
\hline Rajasthan & 1384272 & 97.6 & 76.7 & 23.3 \\
\hline $\begin{array}{l}\text { Uttarakhand } \\
\text { Central }\end{array}$ & 147841 & 87.4 & 68.1 & 31.9 \\
\hline Chhattisgarh & 490703 & 96.9 & 75.8 & 24.2 \\
\hline $\begin{array}{l}\text { Madhya } \\
\text { Pradesh }\end{array}$ & 1375631 & 95.0 & 89.7 & 10.3 \\
\hline $\begin{array}{l}\text { Uttar Pradesh } \\
\text { East }\end{array}$ & 3972262 & 85.6 & 74.1 & 25.9 \\
\hline Bihar & 2087990 & 81.3 & 95.0 & 5.0 \\
\hline Jharkhand & 737983 & 95.4 & 72.8 & 27.2 \\
\hline Odisha & 655820 & 96.2 & 84.0 & 16.0 \\
\hline $\begin{array}{l}\text { West Bengal } \\
\text { North-east }\end{array}$ & 1323129 & 97.8 & 79.5 & 20.5 \\
\hline $\begin{array}{c}\text { Arunachal } \\
\text { Pradesh }\end{array}$ & 18872 & 90.0 & 85.0 & 15.0 \\
\hline Assam & 592973 & 89.9 & 83.7 & 16.3 \\
\hline Manipur & 38028 & 82.3 & 81.0 & 19.0 \\
\hline Meghalaya & 84372 & 57.8 & 77.0 & 23.0 \\
\hline Mizoram & 19440 & 88.4 & 80.0 & 20.0 \\
\hline Nagaland & 19710 & 82.1 & 76.5 & 23.5 \\
\hline Sikkim & 7107 & 99.1 & 65.8 & 34.2 \\
\hline $\begin{array}{l}\text { Tripura } \\
\text { West }\end{array}$ & 50343 & 93.4 & 94.8 & 5.2 \\
\hline $\begin{array}{c}\text { Dadra and } \\
\text { Nagar } \\
\text { Haveli }\end{array}$ & 9077 & 99.5 & 89.2 & 10.8 \\
\hline $\begin{array}{l}\text { Daman and } \\
\text { Diu }\end{array}$ & 3857 & 99.9 & 87.6 & 12.4 \\
\hline Goa & 17955 & 99.8 & 58.9 & 41.1 \\
\hline Gujarat & 1139108 & 99.4 & 37.3 & 62.7 \\
\hline $\begin{array}{l}\text { Maharashtra } \\
\text { South }\end{array}$ & 1726544 & 99.3 & 51.9 & 48.1 \\
\hline $\begin{array}{l}\text { Andaman and } \\
\text { Nicobar }\end{array}$ & 3840 & 97.8 & 100.0 & 0 \\
\hline $\begin{array}{l}\text { Andhra } \\
\text { Pradesh }\end{array}$ & 747243 & 99.4 & 43.4 & 56.6 \\
\hline Karnataka & 911795 & 99.9 & 62.0 & 38.0 \\
\hline Kerala & 484556 & 99.9 & 29.7 & 70.3 \\
\hline Lakshadweep & 845 & 100.0 & 100.0 & 0 \\
\hline Puducherry & 43977 & 100.0 & 76.0 & 24.0 \\
\hline Tamil Nadu & 939547 & 100.0 & 54.6 & 45.4 \\
\hline Telangana & 610191 & 99.9 & 53.6 & 46.4 \\
\hline
\end{tabular}

prescribed formats on the status of the health services performances, human resources, and infrastructure services available in the states. The HMIS portal captures data from public and private institutions in rural and urban areas. Although questions have been raised over the competencies of the HMIS data, studies in the past have affirmed its completeness and quality. ${ }^{22}$

The HMIS format, as a part of the routine process, collected information from all the health facilities. We obtained selective data regarding the total number of MTP and deliveries conducted at public and private institutions. Institutional birth was defined as delivery at either a hospital or clinic (primary health centre or community health centre). Furthermore, information was sought for the percentage of MTP done within 12 weeks and after 12 weeks of pregnancy at public 
Table 2

State-wise distribution of percentage of MTP done at public or private facilities and up to 12 or more than 12 weeks.

\begin{tabular}{|c|c|c|c|c|c|c|}
\hline States & $\begin{array}{l}\text { Total } \\
\text { number of } \\
\text { MTPs }\end{array}$ & $\begin{array}{l}\text { Total number of } \\
\text { spontaneous abortions } \\
\text { reported }\end{array}$ & $\begin{array}{l}\% \text { of MTPs conducted } \\
\text { at public facilities to } \\
\text { total MTP }\end{array}$ & $\begin{array}{l}\% \text { of MTPs conducted at } \\
\text { Private Institutions to } \\
\text { Total MTP }\end{array}$ & $\begin{array}{l}\% \text { MTPs up to } 12 \text { weeks of } \\
\text { Pregnancy to Total MTPs at } \\
\text { Public Institutions }\end{array}$ & $\begin{array}{l}\% \text { MTPs more than } 12 \text { weeks } \\
\text { of Pregnancy to Total MTPs at } \\
\text { Public Institutions }\end{array}$ \\
\hline \multicolumn{7}{|l|}{ North } \\
\hline Chandigarh & 1649 & 1823 & 100.0 & 0 & 80.2 & 19.8 \\
\hline Delhi & 6288 & 23275 & 31.1 & 68.9 & 86.1 & 13.9 \\
\hline Haryana & 13818 & 14683 & 36.3 & 63.7 & 94.0 & 6.0 \\
\hline $\begin{array}{l}\text { Himachal } \\
\text { Pradesh }\end{array}$ & 2818 & 7648 & 54.2 & 45.8 & 87.3 & 12.7 \\
\hline $\begin{array}{l}\text { Jammu and } \\
\text { Kashmir }\end{array}$ & 4784 & 18323 & 79.1 & 20.9 & 93.8 & 6.2 \\
\hline Punjab & 4244 & 18411 & 17.4 & 82.6 & 90.9 & 9.1 \\
\hline Rajasthan & 18866 & 60556 & 78.1 & 21.9 & 95.6 & 4.4 \\
\hline Uttarakhand & 4320 & 3557 & 91.9 & 8.1 & 96.8 & 3.2 \\
\hline \multicolumn{7}{|l|}{ Central } \\
\hline Chhattisgarh & 10179 & 19655 & 79.0 & 21.0 & 92.5 & 7.5 \\
\hline $\begin{array}{l}\text { Madhya } \\
\text { Pradesh }\end{array}$ & 25499 & 39389 & 69.0 & 31.0 & 94.0 & 6.0 \\
\hline Uttar Pradesh & 34582 & 33215 & 79.2 & 20.8 & 92.3 & 7.7 \\
\hline & & \multicolumn{5}{|c|}{ East } \\
\hline Binar & 2493 & 4656 & 15.9 & 84.1 & 88.0 & 12.0 \\
\hline Jharkhand & 4286 & 18323 & 56.4 & 43.6 & 93.1 & 6.9 \\
\hline Odisha & 15963 & 44335 & 83.8 & 16.2 & 97.0 & 3.0 \\
\hline West Bengal & 34907 & 81346 & 61.8 & 38.2 & 88.7 & 11.3 \\
\hline \multicolumn{7}{|l|}{ North-east } \\
\hline $\begin{array}{c}\text { Arunachal } \\
\text { Pradesh }\end{array}$ & 1146 & 297 & 61.0 & 39.0 & 94.6 & 5.4 \\
\hline Assam & 92470 & 27078 & 92.4 & 7.6 & 97.5 & 2.5 \\
\hline Manipur & 3104 & 1729 & 76.0 & 24.0 & 98.0 & 2.0 \\
\hline Meghalaya & 337 & 4283 & 100.0 & 0 & 92.3 & 7.7 \\
\hline Mizoram & 200 & 1121 & 97.6 & 2.4 & 59.0 & 41.0 \\
\hline Nagaland & 579 & 539 & 28.9 & 71.1 & 96.4 & 3.6 \\
\hline Sikkim & 43 & 333 & 100.0 & 0 & 88.4 & 11.6 \\
\hline Tripura & 2180 & 1377 & 100.0 & 0 & 95.5 & 4.5 \\
\hline \multicolumn{7}{|l|}{ West } \\
\hline $\begin{array}{l}\text { Dadra and } \\
\text { Nagar Haveli }\end{array}$ & 162 & 819 & 34.7 & 65.3 & 100.0 & 0 \\
\hline Daman and Diu & 107 & 217 & 48.0 & 52.0 & 100.0 & 0 \\
\hline Goa & 305 & 533 & 40.3 & 59.7 & 92.1 & 7.9 \\
\hline Gujarat & 10180 & 27423 & 70.4 & 29.6 & 86.9 & 13.1 \\
\hline Maharashtra & 38599 & 54588 & 24.9 & 75.1 & 92.5 & 7.5 \\
\hline \multicolumn{7}{|l|}{ South } \\
\hline $\begin{array}{l}\text { Andaman and } \\
\text { Nicobar }\end{array}$ & 185 & 121 & 100.0 & 0 & 90.8 & 9.2 \\
\hline Andhra Pradesh & 2410 & 8958 & 83.4 & 16.6 & 69.2 & 30.8 \\
\hline Karnataka & 16780 & 25753 & 51.1 & 48.9 & 79.8 & 20.2 \\
\hline Kerala & 2019 & 13123 & 19.2 & 80.8 & 75.8 & 24.2 \\
\hline Lakshadweep & 4 & 107 & 100.0 & 0 & 100.0 & 0 \\
\hline Puducherry & 635 & 1026 & 50.0 & 50.0 & 74.3 & 25.7 \\
\hline Tamil Nadu & 30884 & 37178 & 41.0 & 59.0 & 88.9 & 11.1 \\
\hline Telangana & 3903 & 4065 & 95.5 & 4.5 & 65.8 & 34.2 \\
\hline
\end{tabular}

Abbreviations: MTP: Medical Termination of Pregnancy.

institutions. We retrieved data from the standard reports of the key HMIS indicators up to the district-level using the HMIS portal of the National Health Mission. The standard reports of the period between April 2018 and March 2019 were accessed and used for the analysis. The reports of all the states $(n=29)$ and union territories $(n=7)$ were obtained from the portal and dichotomized into regions, namely north, south, east, west, north-east, and central. We do not possess individuallevel data collected at the facilities. Instead, it is the aggregated statelevel data entered into the HMIS system.

\subsection{Statistical analysis}

The analysis was performed in Microsoft Excel. Standard descriptive statistics were calculated and shown region and state-wise. QGIS 3.10 was used for developing the maps. The excel file was linked with QGIS, and then further mapping was done. The cut-offs for the percentage of outcome variables were entered manually for analytical purposes. Different color codes were used to represent the percent deliveries in public and private facilities across different states or union territories. The states with institutional deliveries in public facilities less than $62 \%$ were colored red, between 62 and $84 \%$ were colored yellow, and more than $84 \%$ green. Similarly, the states with institutional deliveries in the private sector less than $15 \%$ were colored red, between 15 and $34 \%$ were colored yellow, and more than $34 \%$ green. However, the percentage of MTP in public or private facilities were depicted using circles of increasing sizes. The states with MTP in public facilities less than $41 \%$, between 42 and $70 \%$, and more than $70 \%$ were shown with increasing sizes of the circles. Similarly, the states with MTP in the private sector less than $24 \%$, between 24 and $52 \%$, and more than $52 \%$ were depicted with increasing size of the circles.

\section{Results}

The tables represent the data of the institutional deliveries and MTP across 29 states and 7 union territories. In almost all the southern states, the states from Western India, and Punjab, Haryana, and North East, i.e., 


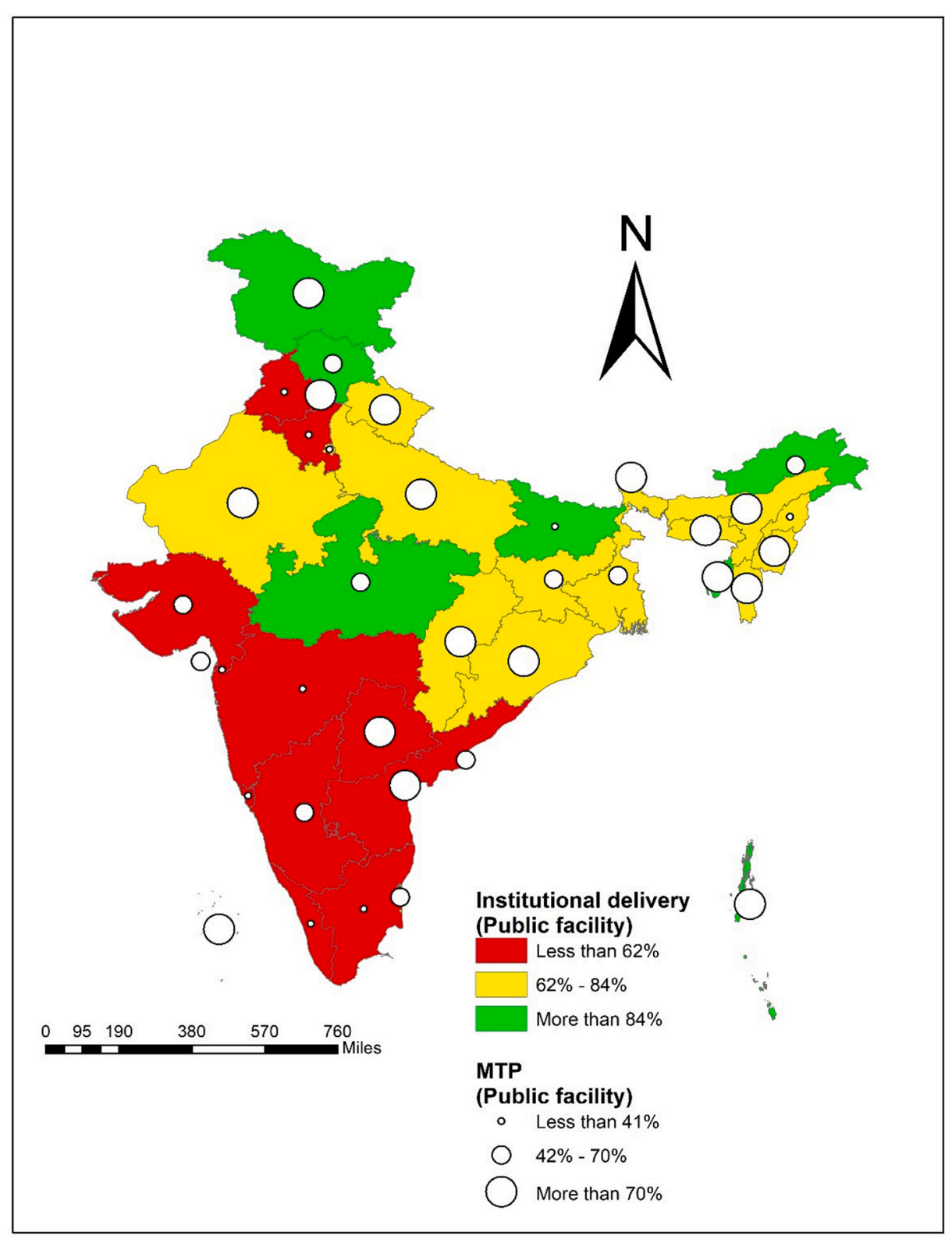

Fig. 1. State-wise distribution of percentage of institutional deliveries and MTP in public facilities. Legend: The states with institutional deliveries less than $62 \%$ were colored red, between 62 and $84 \%$ were colored yellow, and more than $84 \%$ green. The states with MTP less than $41 \%$, between 42 and $70 \%$, and more than $70 \%$ were shown with increasing sizes of the circles. . (For interpretation of the references to color in this figure legend, the reader is referred to the Web version of this article.)

Sikkim, more than one-third of the deliveries were conducted and reported by private institutions (Table 1). On the contrary, states like Jammu and Kashmir, Madhya Pradesh, Bihar, and Tripura reported more than $90 \%$ of deliveries at public institutions.

The data found that 3,90,928 MTP were reported in India (April 2018-March 2019), giving an estimated abortion (spontaneous + MTP) rate of 2.84 per 1000 women of reproductive years (15-49 years). In states like Kerala, Maharashtra, and Bihar, more than three-fourths of abortions (MTP) were reported from private facilities (Table 2). Though most of the MTP reported from public institutions took place within 12 weeks of pregnancy at all places, except for Mizoram, Andhra Pradesh, and Telangana, where $30-40 \%$ of the MTP happened after the first trimester.

Fig. 1 represents the institutional deliveries and MTP in public facilities in the states of India. It was found that states like Punjab, Haryana, Gujarat, Maharashtra, Telangana, Andhra Pradesh, Karnataka, Goa, Kerala, and Tamil Nadu had less than $62 \%$ of institutional deliveries in public facilities. Apart from that, less than $41 \%$ of MTP were practiced in public facilities in states like Punjab, Haryana, Delhi, Bihar, Dadar and Nagar Haveli, Maharashtra, Kerala, Tamil Nadu, and

\section{Nagaland.}

Fig. 2 represents the institutional deliveries and MTP in private facilities in the states of India. It was revealed that states like Jammu and Kashmir, Himachal Pradesh, Bihar, Arunachal Pradesh, and Tripura had less than $15 \%$ of institutional deliveries in private facilities. Moreover, states like Haryana, Punjab, Delhi, Dadar and Nagar Haveli, Maharashtra, Goa, Kerala, Tamil Nadu, Bihar, and Nagaland had more than $52 \%$ of MTP practiced in private facilities.

\section{Discussion}

India made significant strides in improving the maternal and child health condition in the country in the last decade. As a result, the maternal mortality rate in the country decreased from 212 in 2010 to 172 in 2019. Furthermore, the institutional delivery rate improved significantly from $50 \%$ in 2000 to $95 \%$ in $2019 .{ }^{23}$ Multiple factors underpinned to this achievement include the introduction of a conditional maternity benefit scheme, free ambulance and facility care under maternal and child safety programs, etc. ${ }^{8}$ A large percentage of deliveries occurred in private hospitals in the western or southern states 


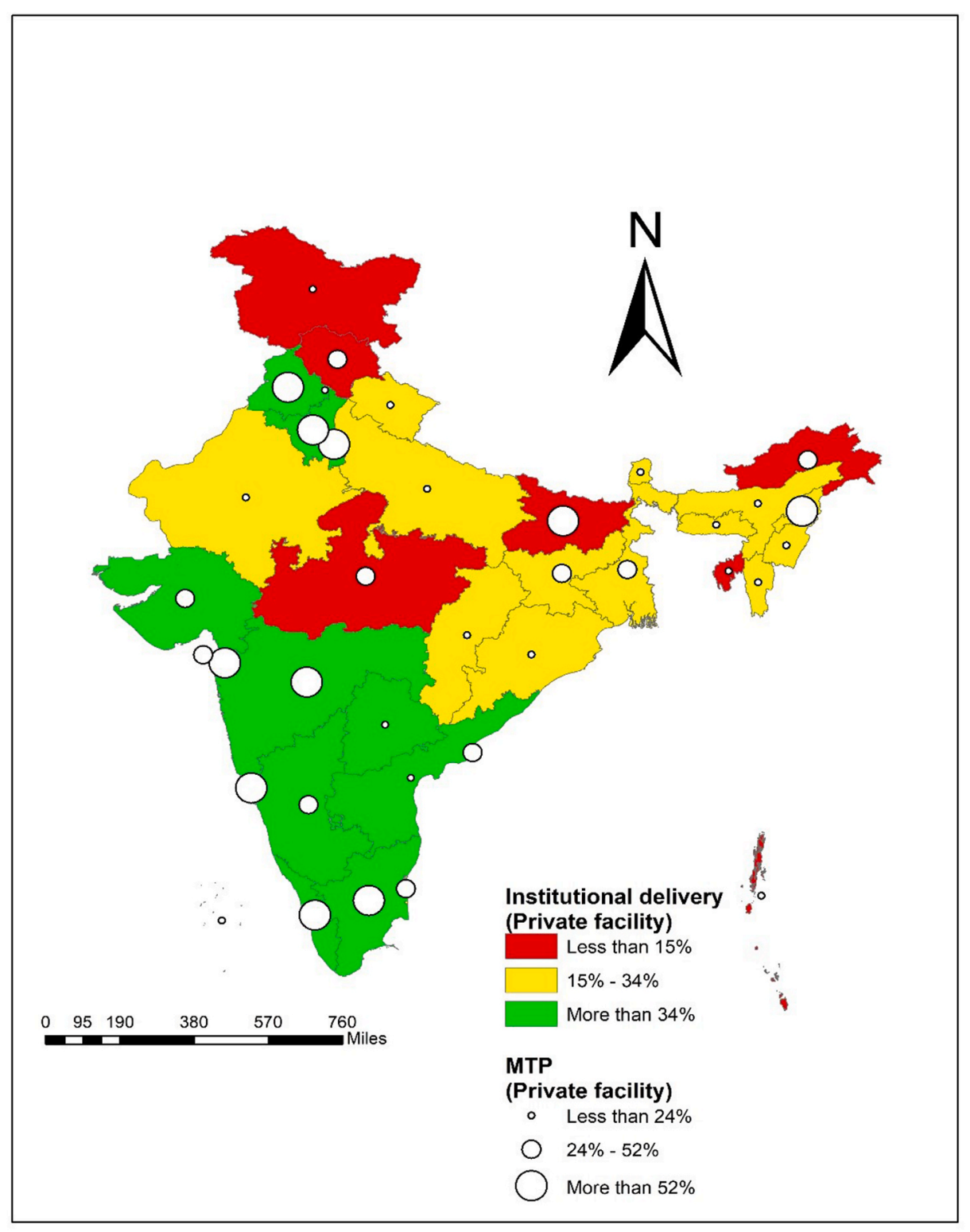

Fig. 2. State-wise distribution of percentage of institutional deliveries and MTP in private facilities. Legend: The states with institutional deliveries less than $15 \%$ were colored red, between $15-34 \%$ were colored yellow, and more than $34 \%$ green. The states with MTP less than $24 \%$, between $24-52 \%$, and more than $52 \%$ were depicted with increasing size of the circles. . (For interpretation of the references to color in this figure legend, the reader is referred to the Web version of this article.)

like Punjab, Haryana, Kerala, Telangana, Tamil Nadu, Gujarat, Maharashtra, Goa, and Andhra Pradesh. This is largely attributable to the improved household, or family income in these states as the cost of hospitalization and doctor fees are quite high, which is beyond the capacity of millions to pay in other parts of the country. ${ }^{24}$

Our estimations of the abortion (spontaneous + MTP) rate of 2.84 per 1000 women is one-sixteenth of that reported in a Lancet study (47.0 per 1000 women). The facility-based abortion estimates in the Lancet study (3.4 million) are more than five times the number reported in ours (0.59 million). ${ }^{25}$ The abortion rate in the Lancet study of 2018 was estimated by three components: facility-based abortions, medical abortions outside facilities, and non-medical abortions outside the facilities. The study estimated facility-based abortions from the national health facility survey 2015 of 4001 public and private health facilities in six Indian states (Assam, Bihar, Gujarat, Madhya Pradesh, Tamil Nadu, and Uttar Pradesh) and from the clinic data of non-governmental organizations (NGO). Similarly, national medication abortion drug sales and distribution data were obtained from IMS Health and NGOs in the Lancet study. An indirect technique employing findings from community-based study findings were used to calculate non-medical abortions outside the facilities. The study estimated $15 \cdot 6$ million abortions (14.1 million-17.3 million) in India in 2015. ${ }^{25}$ Furthermore, our estimates are lower than the ones reported to occur in the government facilities by the National Family Health Survey-4 $(7,01,415) .^{23}$ This could be because of high over-the-counter access to medical abortion drugs, like mifepristone and misoprostol, without prescriptions via chemists or informal vendors. ${ }^{25}$ However, our paper does not intend to assess the incidence of abortions in the country.

High abortion rates in the studies (Lancet study and National Health Survey) reflect the high unmet needs of contraceptives or unintended pregnancies. This suggests the need for improved contraceptive services and access to such services by women across all geographies and social classes. High contraceptive failures rate due to the use of conventional methods or incorrect use of contraceptives are the additional contributing factors to abortions or unintended pregnancies. ${ }^{25}$

The national family health survey-4 reported that more than $50 \%$ $(52 \%)$ of the abortions in India take place in the private sector. ${ }^{23}$ In the Lancet study, it was reiterated that private facilities contributed to around three-fourths of the surgical abortions compared to one-fourths by public facilities. ${ }^{25}$ On the contrary, $91 \%$ of the medical abortions in the country took place outside the facilities compared to $7 \%$ in the private and $2 \%$ in the public facilities. ${ }^{25}$ A study estimated that $73 \%$ of 
over 15 million abortions in India are induced through medical abortion outside of facilities, which have not been recorded in our study. A large chunk of these outside facilities medical abortions relies on pharmacists. $^{26}$

This differential access to private facilities for MTP can be attributed to multiple causes. Firstly, sex-selective abortions and restricted access to abortions by providers in certified facilities that do not provide services to women if they come alone or if the spouse or a close relative does not give consent push women towards private and uncertified facilities. Secondly, this is further aggravated by the low decision-making capacity of women, controlled by husbands or other family members, and the family's resort to unsafe providers for abortions to maintain confidentiality and privacy. Lastly, the lack of adequate facilities for abortion and good quality care, counselling and confidentiality in the public sector are additional reasons for limited access to public facilities by women in many states. ${ }^{27}$

Apart from the states in the south (Kerala, Tamil Nadu, etc.) or western India (Maharashtra, Gujarat, etc.), states like Bihar, Nagaland, and Union territories like Delhi and Dadra and Nager Haveli had a high percentage of abortion in the private sector. Previous studies highlighted that due to the lack of safe and adequate abortion services in the public sector in Bihar, women turn to the private sector for abortion despite legal constraints in uncertified private centers and financial burden on women. ${ }^{28,29}$ Some of the gap areas identified by the previous research include an inadequate number of safe abortion facilities within reach of poor women in rural or urban areas, inadequate registered abortion providers or facilities, and post-abortion counselling on contraceptives. This is an issue of concern as $13 \%$ of maternal deaths are due to unsafe abortion. ${ }^{30}$

\subsection{Limitations}

The study results should be interpreted in view of certain limitations. Firstly, the study was conducted on secondary data from HMIS, which does not include the complete data from the private sector and pharmacists. So, there is a risk of missing out on a certain figure of such abortions happening in private clinics/hospitals or through medications taken from pharmacies. Secondary, due to a lack of individual-level data, we could not associate the socio-economic factors with a high prevalence of institutional deliveries/abortions in the private sector. Lastly, the current data is for one year, and it's difficult to observe the trend of access to private or public sectors for deliveries or abortions. Hence, our subsequent paper with elaborated data of differential access over the last decade may help us understand the trends.

\section{Conclusions}

The study observed a difference in access to deliveries and abortions among Indian populations. A large part of women underwent deliveries as well as abortions in the private sector in the southern and western states of India like Kerala, Tamil Nadu, Andhra Pradesh, Goa, and Maharashtra. Women in most of the northern states opted for public health facilities for deliveries as well as abortions, except Punjab and Haryana. On the contrary, states like Bihar, Nagaland, and Union territories like Delhi and Dadra and Nager Haveli had a high percentage of abortions in the private sector and deliveries in public health facilities. The government and policy-makers need to understand this differential access and assess the gap areas leading to limited access by women to public facilities for MTP.

\section{Role of funding source}

We did not receive any funding for this study.

\section{Authors' contribution}

Shantanu Sharma conceptualized and wrote the full manuscript, Param and Rajesh Kumar Singh obtained and analyzed the data, Ajit contributed to the methodology section, and designed the figures, Sunil Mehra reviewed and edited the final version of the manuscript.

\section{Declaration of competing interest}

The authors declare that there is no conflict of interest.

\section{References}

1 United Nations Department of Economic and Social Affairs/Population Division. World population to 2300. New york. Available from https://www.un.org/de velopment/desa/pd/sites/www.un.org.development.desa.pd/files/files/documents /2020/Jan/un 2002 world population to 2300.pdf; 2004.

2 Raghavendra M, Das AK. India Steps Up to Strengthen Maternal Health and Achieve SDG 3. Accessed 11 September 2020. Available from: https://www.globalpolicyjo urnal.com/blog/12/07/2019/india-steps-strengthen-maternal-health-and-achieve -sdg-3.

3 World Health Organization. India has achieved groundbreaking success in reducing maternal mortality. WHO. Geneva. Accessed 11 September 2020. Available from: https://www.who.int/southeastasia/news/detail/10-06-2018-india-has-achieved-g roundbreaking-success-in-reducing-maternal-mortality.

4 United Nations and Government of India. Sustainable development Goals index and dashboard 2019-2020. NITI ayog, New Delhi. Available from https://niti.gov.in/sites /default/files/SDG-India-Index-2.0_27-Dec.pdf; 2019. Accessed March 10, 2020.

5 Barman B, Roy A, Zaveri A, Saha J, Chouhan P. Determining factors of institutional delivery in India: a study from national family health survey-4 (2015-16). Clinical Epidemiology and Global Health. 2020 May 16 (in press).

6 Joe W, Perkins JM, Kumar S, Rajpal S, Subramanian SV. Institutional delivery in India, 2004-14: unravelling the equity-enhancing contributions of the public sector. Health Pol Plann. 2018;33(5):645-653.

7 Yadav V, Kumar S, Balasubramaniam S, et al. Facilitators and barriers to participation of private sector health facilities in government-led schemes for maternity services in India: a qualitative study. BMJ Open. 2017;7(6), e017092.

8 Salve HR, Charlette L, Kankaria A, Rai SK, Krishnan A, Kant S. Improving access to institutional delivery through Janani shishu Suraksha karyakram: evidence from rural Haryana, north India. Indian J Community Med. 2017;42(2):73-76.

9 Thongkong N, Van de Poel E, Roy SS, Rath S, Tanja A, Houweling J. How equitable is the uptake of conditional cash transfers for maternity care in India? Evidence from the Janani Suraksha Yojana scheme in Odisha and Jharkhand. Int J Equity Health. 2017;16(48).

10 Mishra PS, Kumar P, Srivastava S. Regional inequality in the Janani Suraksha Yojana (JSY) coverage in India: A Geo-spatial Analysis. https://assets.researchsquare.com/ files/rs-36683/v1_stamped.pdf.

11 Katke RD, Prabhudesai AA. Socio-epidemiological factors of medical termination of pregnancy: an overview in a tertiary care institute. Int J Res Med Sci. 2016;4: 1061-1064.

12 Chowdhury S. Developing a scale to measure obstetric and gynaecology professionals' attitudes towards medical termination of pregnancy and emergency contraception services, Kerala, India. J Health Manag. 2017;19(2):304-319.

13 Bhattacharya S, Bashar MA, Singh A. So near, yet so far: access to safe abortion services remains elusive for poor women in India. BMJ Case Rep. 2017.

14 Creanga AA, Singh KK, Li Q, Fruhauf T, Tsui AO. Changes in abortion service provision in Bihar and Jharkhand states, India between 2004 and 2013. PloS One. 2018;13(6), e0197300.

15 Moore AM, Stillman M, Shekhar C, et al. Provision of medical methods of abortion in facilities in India in 2015: a six state comparison. Global Publ Health. 2019;14(12): 1757-1769.

16 The World Bank. Total Population. Accessed 11 January 2021. Available from https://data.worldbank.org/indicator/SP.POP.TOTL?locations=IN.

17 States and Union Territories. Accessed 10 December 2020. Available from: https:// knowindia.gov.in/states-uts/.

18 Chokshi M, Patil B, Khanna R, et al. Health systems in India. J Perinatol. 2016;36: S9-S12.

19 Loh LC, Ugarte-Gil C, Darko K. Private sector contributions and their effect on physician emigration in the developing world. Bull World Health Organ. 2013;91: $227-233$.

20 Dehury RK, Samal J, Coutinho S, Dehury P. How does the largely unregulated private health sector impact the Indian mass? J Health Manag. 2019;21(3):383-393.

21 Ministry of Health and Family Welfare. Health Management Information System. htt ps://nrhm-mis.nic.in/SitePages/HMIS-Download.aspx.

22 Sharma A, Rana SK, Prinja S, Kumar R. Quality of health management information system for maternal \& child health care in Haryana state, India. PloS One. 2016;11 (2), e0148449.

23 International Institute for Population Sciences (IIPS) and ICF. National Family Health Survey (NFHS-4), 2015-16: India. Mumbai: IIPS; 2017.

24 Rayhan SK. Does delivery in private hospitals contribute largely to Caesarean Section births? A path analysis using generalised structural equation modelling. PloS One. 2020;15(10), e0239649. 
25 Singh S, Shekhar C, Acharya R, et al. The incidence of abortion and unintended pregnancy in India. The Lancet Global Health. 2018;6(1):e111-e120, 2015.

26 Diamond-Smith N, Percher J, Saxena M, Dwivedi P, Srivastava A. Knowledge, provision of information and barriers to high quality medication abortion provision by pharmacists in Uttar Pradesh, India. BMC Health Serv Res. 2019;19(476).

27 Duggal R, Ramachandran V. The abortion assessment project-India: key findings and recommendations. Reprod Health Matters. 2004;12(S24):122-129.
28 Banerjee SK, Andersen KL, Navin D, Mathias G. Expanding availability of safe abortion services through private sector accreditation: a case study of the Yukti Yojana program in Bihar, India. Reprod Health. 2015;12(104).

29 Stillman M, Alagarajan M, Moore AM, Singh S, Ball H. Unintended pregnancy, abortion, and post-abortion care in Bihar, India. https://www.guttmacher.

org/report/unintended-pregnancy-abortion-postabortion-care-bihar-india-2015\#; 2015.

30 Park K. Park's Textbook of Preventive and Social Medicine. $25^{\text {th }}$ edition. Jabalpur, India: Bhanot publications; 2019:612 (Chapter 10). 